\title{
Timelines, expected outcomes and management procedures of the Marine Strategy Framework Directive. A discussion of spatial and temporal scales in the management and adaptation to changing climate.
}

Eva Roth, University of Southern Denmark, Esbjerg, Denmark ( er@sam.sdu.dk)

Tim O'Higgins, Scottish Association for Marine Science, Oban, Scotland.(tim.o'higgins@sams.ac.uk)

\begin{abstract}
:
Existing and emerging EU legislation requires member states to adopt the Ecosystem Approach (EA) for the management of their seas and to achieve Good Environmental Status (GES) by 2020. The EA is an holistic approach to management and requires the integrated management of ecosystems, human beings, their governance structures and institutions. The Marine Strategy Framework Directive (EU 2008) also stresses the importance of adaptive management. The effective practice of the EA in the Baltic Sea will require integration of management of fish stocks with other elements of environmental management. The process of setting achievable environmental targets must also account for highly uncertain changes to the physical and biological environment driven by climate.

This paper clarifies the scope and scale of obligations under the MSFD. It illustrates the spatial and temporal challenges involved in conforming to GES. It identifies characteristics of achievable environmental targets under the MSFD. We combine a literature review on fisheries, eutrophication and climate change with the novel technique of Decision Space Analysis. Using a matrix of timeframes and spatial scales for biological issues and legal processes in the Baltic Sea the elements necessary to set feasible targets for GES were analysed. The methodology focuses on the spatial and temporal consistencies and inconsistencies of ecosystems vis-à-vis the governance systems presently guiding the European seas, i.e. member states, cooperative structures tied to the International Conventions and the European Commission.
\end{abstract}

Keywords: Marine Strategy Framework Directive, Ecosystem Approach, Baltic, Cod, Eutrophication

\section{Introduction}

In 2008 the Marine Strategy Framework Directive (MSFD) came into force (EU 2008). This Directive is the first comprehensive piece of EU legislation enforcing an Ecosystem Approach to management. The overall aim of the MSFD is to promote sustainable use of the seas and it is regarded as the "environmental pillar" of the EU Integrated Maritime Policy and is intended to be coherent with the developing Common Fisheries Policy (CFP). The scope of the Directive is comprehensive, encompassing most human activities relating to the seas and providing a more coherent basis for management and protection of the marine environment. The Directive builds on existing policy unifying the goals of previous legislation including the Birds Directive (EU 1979), the Habitats directive (EU 1992), and the Water Framework Directive (EU 2000). The MSFD builds on existing policy by introducing the Ecosystem Approach (to management) and reflects a paradigm shift to a more integrated management recognising the connections between the environment and human activities. 
Though there are many definitions of an Ecosystem Approach there is no single model of how this developing concept should be put into practice. One key component of the approach is the recognition of ecosystem services which are the aspects of ecosystems utilised (actively or passively) to produce human well being (Fisher et al. 2009). Human welfare on the individual level as well as at the aggregate level of societies and economies are entirely dependent on the supply of ecosystem services. Food, water, air and habitable climate are all ecosystem services, yet humans very often adversely affect the ecosystems which provide these services. The ecosystem approach recognises that ecosystem services are essential to human activities and an increased awareness of the values associated with these services is developing (Costanza 1997; MEA 2005). The Ecosystem Approach to management, synonymous with "Ecosystem Approach" and "Ecosystem Based Management", is based on the recognition that human activities and natural process are linked and that we live in coupled social-ecological systems (Daily 1997; Daily \& Walker 2000; Boumans et al. 2002; Ehrlich \& Ehrlich 2008).

The coming into force of the MSFD results in a legal requirement for European Union Member States to put the Ecosystem Approach into practice. This provides an immense challenge to scientists (social and ecological) and policy makers alike. The working definition of the Ecosystem Approach which has been adopted by the KnowSeas (FP7) project is...

"a resource planning and management approach that integrates the connections between land, air and water and all living things, including people, their activities and institutions." 1

This is a broad definition and the key aspect is the integration of the connections between natural resources (biotic and abiotic) and human activities. One challenge to the implementation of an Ecosystem Approach is the management of highly complex social-ecological systems which exhibit non linear and chaotic behaviour and where huge uncertainty pervades. A second challenge is the integration of ecosystem services into the existing economic framework. Developing methods for integrating the supply of nature's services with existing economic activities is not simple. To examine ecosystem services it is essential to classify them according to a typology. Many typologies for ecosystem services have emerged (Costanza 1997; MEA 2005; Boyd \& Bahnzahf 2007, Fisher \& Turner 2008) but the joint nature of many services (i.e. many ecosystem processes combine to deliver an ecosystem service) has meant that many typologies (eg. Costanza 1997; Millennium Ecosystem Assessment 2005) lead to double counting and cannot be integrated with economic accounting practices. The "Classification of Ecosystem Services for Decision Making" (Fisher et al. 2009) avoids double counting by providing a clear delineation between intermediate services, final services and benefits. This scheme also recognises that ecosystem services are benefit dependent allowing the focused selection of benefits and the final and intermediate services which underpin them and will provide a sound basis for the support of the MSFD.

\footnotetext{
${ }^{1}$ A full rationale for the choice of the definition is contained in KnowSeas Deliverable 2.1 which may be obtained by contacting the authors.
} 


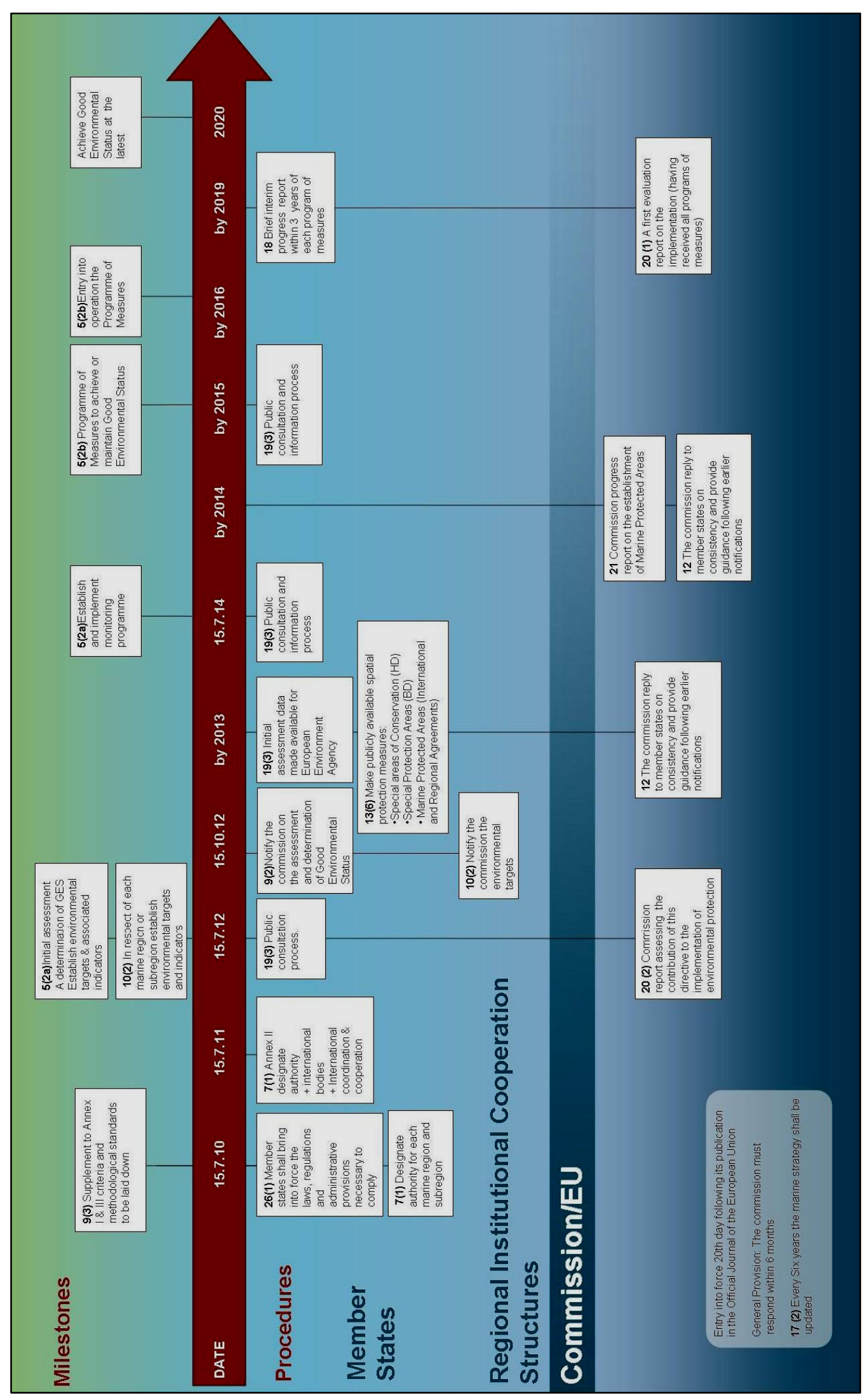

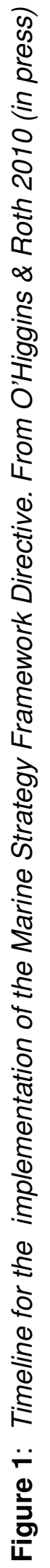




\section{Implementation of the Directive}

A timeline showing the obligations of the European Commission and the European Union member states under the MSFD is set out in Figure 1. The major obligation of member states under the MSFD is achievement of Good Environmental Status (GES) by 2020. GES is to be assessed on the basis of 11 descriptors contained in Annex 1 of the Directive (Table 1). The descriptors reflect a mixture of environmental and anthropocentric concerns. Aspects of human welfare are particularly apparent in descriptor 3 concerning commercial fisheries and in descriptors 8 and 9 which deal with contaminants. Other descriptors particularly, descriptor 4 on marine food webs have an ecosystem bias. Some of the descriptors follow naturally from existing legislation (eg. 1,3,5.) while others such as descriptor 10 on marine litter and descriptor 11 on marine noise reflect emerging concerns about Europe's marine environment. Overall the descriptors are fairly comprehensive and show some overlap, which reflects the joint nature of the ecosystem services they are designed to protect.

There are five major scientific steps required to deliver the goal of GES. The first, definition of methodological criteria and standards, has already been delivered in a recent EU decision (EU 2010). The Commission decision on the descriptors recognises the requirements for additional scientific understanding to assess GES and provides detail on the criteria to be used to assess GES.

The second major scientific step required by the Directive is setting targets and indicators which must be achieved by July 2012. These targets will establish the vision for what "Good Environmental Status" should resemble and will be subject to public consultation. The broad scope of the descriptors leads to potentially conflicting objectives, for example maintaining all elements of the food web at normal levels is not consistent with pursuing Maximum Sustainable Yield in fisheries. Thus the process of stakeholder engagement will be critical to determination of the vision for GES. Once the targets are established the remaining steps involve assessment of the current situation through monitoring (by July 2014); development (by 2015) and implementation (by 2016) of a program of measures leaving four years to reach the target of GES by 2020.

Given the tight timeframe for the achievement of GES and the legal requirement to achieve this status, it is essential to take into account the spatial and temporal scales of the natural and social phenomena being addressed by GES when setting targets. We have developed the technique of Decision Space Analysis to address issues of temporal and spatial scale in management of the marine environment.

\section{Decision Space Analysis: application of the MSFD in the Baltic}

Figure 2 illustrates a Decision Space Analysis map of the Baltic focused on the issues of cod fishing and eutrophication. The map uses a variant of the classic Driver Pressure State Impact Response (DPSIR) causal framework for analysis (which has been adopted by the European Environment Agency). In this modified version of the framework the Impact (I) is replaced with Welfare $(\mathrm{W})$ to avoid ambiguity between environmental and economic impacts.

The aim of the tool is to lead to informed decision making by communicating mismatches in spatial and temporal scale to decision makers. In this example we focus on the interlinked problems of cod fisheries and eutrophication in the Baltic Sea. Extensive eutrophication and 
hypoxia in the Baltic have been widely studied and are related to hydrographic as well as anthropogenic phenomena (see Conley et al. 2009 for review). The degree of hypoxia effects cod recruitment by influencing the spawning volume of water capable of supporting successful development of cod eggs (MacKenzie et al. 2007). The Ecosystem Approach should account for the complex interactions between the physical and biological systems and integrate the social system through management.

Table 1: The environmental scope of the directive is given by the descriptors of Good Environmental Status from Annex I of the MSFD.

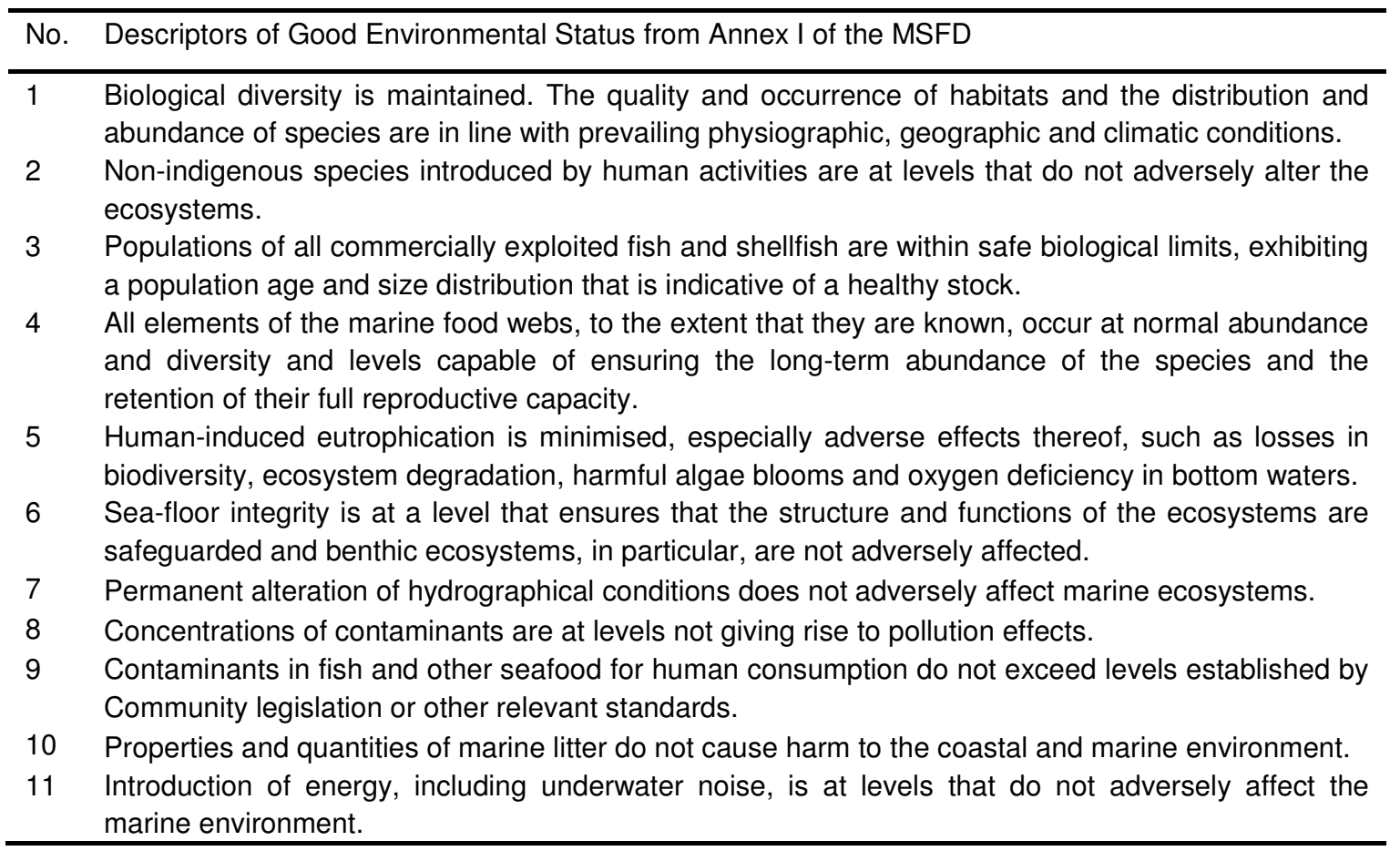

For cod, the major pressure is catch (symbolised by the cod image in the red oval) and the the state is represented by stock size (symbolised by the cod image). The size of the symbols is scaled based on the most recently available catch data for each of the ICES statistical area (ICES 2010). The stocks are assessed for the eastern and western areas separately, hence two symbols are used in the map. Total EU fishery subsidy (under the CFP) is used as a proxy for the welfare generated by the fishery. Data are based at the NUTS III level (this EU Nomenclature of Territorial Units for Statistics) and the data are derived from an online database of EU fishery subsidy (http://fishsubsidy.org). The potential for response is mapped according to the jurisdiction of legislative instruments. For the MSFD the member state EEZs are shown as light blue areas delineated by black. Areas under national legislation where the MSFD does not apply are shown in darker blue. Current cod closure areas are shown in dark green.

For eutrophication, the main pressures are nutrient inputs. The symbols (red letters $\mathrm{N}$ and $\mathrm{P}$ ) are scaled according to measured riverine nutrient loads using data from the geospatial portal of HELCOM (http://maps.helcom.fi/website/DataDelivery/viewer.htm). Eutrophication State is illustrated by the extent of anoxia and hypoxia in 2009 (georeferenced from Hansson et al., 2009). As with the cod example, potential for response is mapped according to the 
legislative jurisdiction. The Water Framework Directive is delineated in dashed red (filled with yellow on land and light green in coastal waters) and areas under national legislation are shown in red.

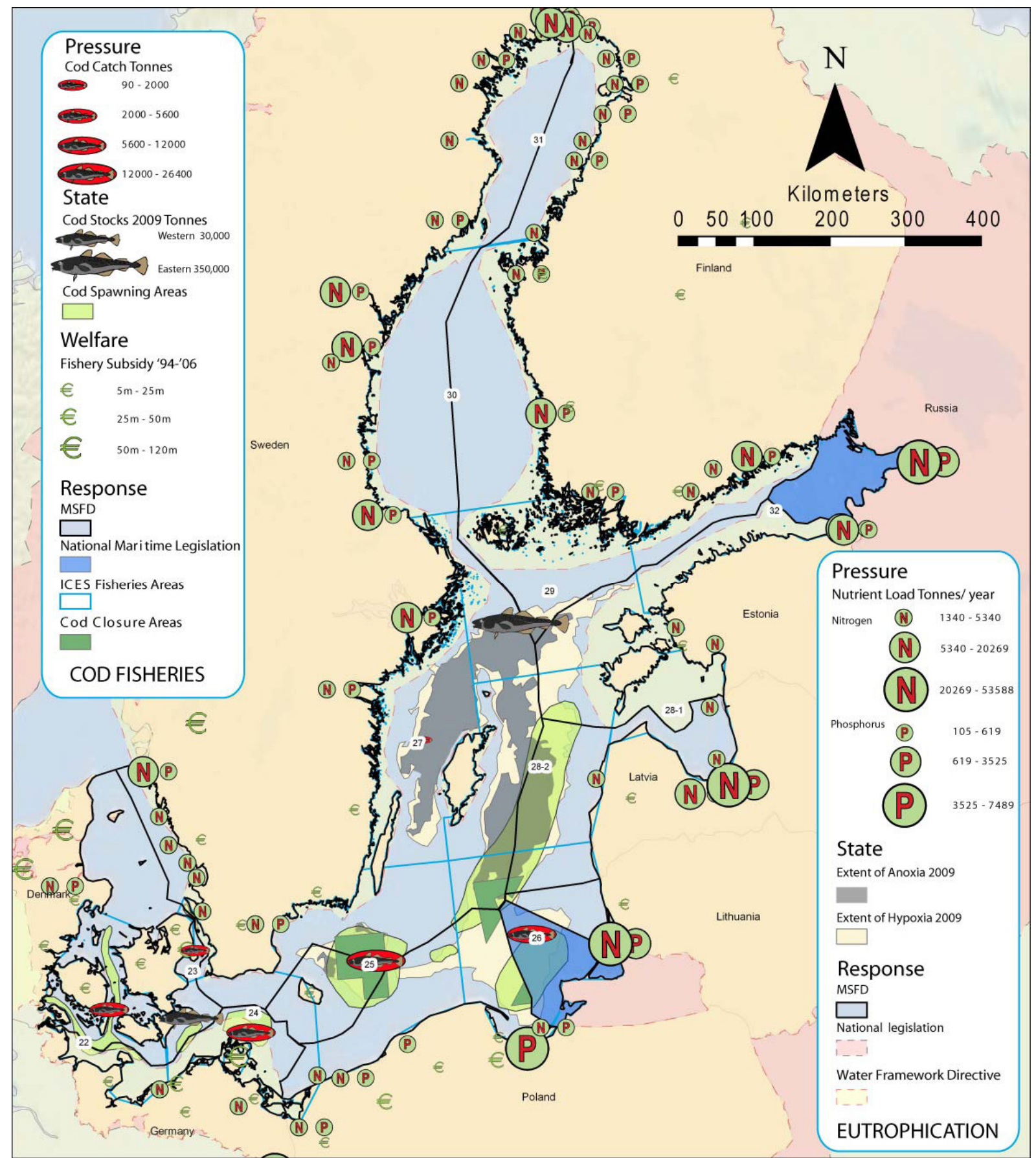

Figure 2: Decision Space Analysis map for cod fisheries and eutrophication in the Baltic Sea (a detailed explanation is contained in the text). From O'Higgins \& Roth 2010 (in press)

The map serves as a decision support tool, allowing easy reliable and informative visualisation of the geographic scope and scale of the two problems as well as the sphere of influence of the relevant legislation. 


\section{Temporal considerations}

Coupled atmosphere-ocean models predict a gradual freshening of the Baltic sea with salinity in the Baltic to decrease by $7-47 \%$ by the year 2100 (HELCOM 2007). Though there is a high degree of uncertainty in the timing and magnitude of the changes, even under rapid change and high fishing pressure scenarios total crashes in the eastern Baltic cod stock are not expected to occur within the timeframe of the MSFD (Roekmann et al. 2005).

Similarly in the case of eutrophication, despite great efforts to reduce nutrient loads to the Baltic Sea system, naturally long residence time ( 30 years) and continuing fluxes combined with increased nutrient influxes predicted through increased annual freshwater run-off mean that rapid reversal of existing eutrophication conditions is unrealistic.

Targets for environmental management in the Baltic must be set taking in to account the long term processes already in place and the spatial constraints of the legislative jurisdiction. The environmental state of the Baltic is unlikely to improve on short timescales thus achievable targets for GES should not be too ambitious in the short term. Nevertheless for future improvements in the Baltic regulating the pressures and drivers that produce environmental state changes may secure improved environmental status in the future. Every component of the ecosystem cannot be maximised and the Ecosystem Approach will require member states to identify and prioritise the types of services for which they wish to manage their ecosystems.

\section{Conclusions}

The MSFD places a heavy scientific burden and strict time constraints on EU member states over the course of the coming decade. Achievement of an Ecosystem Approach will require management for ecosystem services and will require value judgements on the targets for GES. Within the Baltic, management targets must take into account the locked in processes of climate change and eutrophication. Gradual changes in the prevailing physical and biological oceanic conditions caused by global climate change will affect baseline conditions and the achievement of GES and will require adaptive management and adapting human expectations.

\section{Acknowledgements}

The research leading to these results has received funding from the European Community's Seventh Framework Programme [FP7/2007-2013] under grant agreement number 226675. The KnowSeas project is affiliated with LOICZ and LWEC. The authors would like to thank Linda and Cáit O'Higgins and Flemming Roth for their patience.

\section{References}

Boumans, R., R.Costanza, J.Farley, M.A.Wilson, , R. Portela, J.Rotmans, F.Villa, M. Grasso. 2002. Modeling the dynamics of the integrated earth system and the value of global ecosystem services using the GUMBO model. Ecological Economics 41:529-560.

Boyd, J. and S. Banzhaf. 2007. What are ecosystem services? The need for standardized environmental accounting units. Ecological Economics 63:616-626.

Conley, D.J., Björk, S., Bonsdorff, E., Catstensen, J., Destouni, G., Custafsson, B.G., Hietanen, S., Kortekaaas, M., Kuosa, H., Meier, H.E.M., Müller-Karulis, B.., Nordber, K., 
Norkko, A., Nürnbetg, G., Pitkänen, H., Rabalais, N.N., Rosenberg, R., Savchuk, O.P., Slomp, C.P., Voss, M., Wulff, F., and Zillen, L. 2009. Hypoxia related processes in the Blatic Sea. Environmental Science and Technology 43 3412-3420

Constanza, R., R. d'Arge , R. deGroot, S. Farber, M.Grasso, B. Hannon, K. Limburg, S. Naeem, R.V. O'Neill, J. Paruelo, G.R. Raskin, P. Sutton, and M. Van den Belt. 1997. The value of the world's ecosystem services and natural capital. Nature 387:253-260

Daily, G.C. 1997. Nature's Services: Societal Dependence on Natural Ecosystems. Island Press, Washington, D.C. 392pp.

Daily, G.C. and B.H.Walker. 2000. Seeking the great transition. Nature 403:243-245

Ehrlich, P.R., and A.H. Ehrlich. 2008. Nature's economy and the human economy. Environmental Resource Economics 39:9-16

EU 1979 Directive number 409 of 1979, Official Journal of 25 April 1979

EU 1992 Directive number 43 of 1992, Official Journal of 22 July 1992

EU 2000 Directive number 60 of 2000, Official Journal of 22 December 2000

EU 2008 Directive number 56 of 2008, Official Journal of 17 June 2008

EU 2010 Decision number xx of 2010, Official Journal of xx August 2010

Fisher, B and R.K. Turner. 2008. Ecosystem services: classification for valuation, Biological Conservation 141:1167-1169

Hansson, M., Axe, P., Anserson, L. 2009. Extent of hypoxia in the Baltic Sea 1960-2009. SMHI Dnr Mo 2009-124

ICES 2010. Report of the ICES Advisory Committee, 2010. ICES Advice, 2010. Book 8

HELCOM. 2007. Climate Change in the Baltic Sea Area- HELCOM Thematic Assessment in 2007. Baltic Sea Environment Proceedings 111

Mackenzie, B.R., Gislason, H., Möllman, C., Köster, F.W. 2007. Impactof $21^{\text {st }}$ century climate change on Baltic Sea fish community and fisheries. Global Change Biology 131348 1367

Millennium Ecosystem Assessment. 2005. Ecosystems and human well being: Wetlands and water synthesis. World Resources Institute, Washington D.C. 
O'Higgins. T \& Roth, E. 2010. Integrating the CFP and the Marine Strategy for the Baltic. Discussion of the spatial and Temporal Scales in the management and adaptation to climate change. Global Change and Baltic Coastal Zones (in press) 